\title{
APRESENTAÇÃO DO DOSSIÊ: EDUCAÇÃO E PRIVAÇÃO DE LIBERDADE
}

\author{
Ana Cláudia Ferreira Godinho(iD) e Elionaldo Fernandes Julião
}

No atual debate público brasileiro, temos acompanhado os argumentos de grupos conservadores em defesa de medidas de endurecimento das políticas penais e de restrição e privação de liberdade. Recentemente, o atual ministro da Justiça e Segurança Pública propôs mudanças, conhecidas como "Pacote Anticrime" que seguem nesta direção.

Nos últimos anos, são frequentes as manifestações de políticos, de uma mídia sensacionalista e de uma parcela da sociedade conservadora que inclusive defende a revisão do Estatuto da Criança e do Adolescente - ECA (Brasil, 1990), redução da maioridade penal e de propostas que alteram o Código Penal brasileiro, principalmente que dificultem a progressão de regime daqueles que cumprem pena e ou medidas socioeducativas de privação de liberdade.

Em um país que quadriplicou a população prisional em duas décadas e hoje tem uma ocupação de quase $200 \%$ no sistema prisional, dificultar a progressão de regime e reduzir a maioridade penal significa agravar a superpopulação e o encarceramento em massa que já enfrentamos no país. Além disso, o pacote ministerial facilita a defesa de policiais, justificando, no exercício da sua atividade, matarem pessoas.

Se considerarmos que a principal causa de violência letal contra jovens no Brasil é de ações policiais, segundo o Atlas da Violência (2018), a proposta do ministério é preocupante, pois, ao invés de intimidar, despreocupa os principais agentes da violência letal contra jovens.

Nesse contexto, a publicação de um dossiê sobre a educação de jovens e adultos (EJA) em situação de restrição e privação de liberdade nos parece uma estratégia de resistência e defesa dos direitos humanos. A ampla divulgação de pesquisas qualitativas relacionadas ao sistema socioeducativo e ao sistema prisional, apresentadas nos artigos que compõem este número da revista Reflexão e Ação, é importante para compreender o reconhecimento da educação como direito humano fundamental e subjetivo, reconhecer os seus avanços no âmbito legal, assim como na produção de conhecimento sobre o tema.

O reconhecimento da educação como direito da pessoa privada de liberdade, desde a Lei de Execução Penal (BRASIL, 1984), que previu a educação como parte da assistência ao preso, contribuiu para a oferta escolar no sistema prisional, ainda que timidamente. Passadas três décadas da sua promulgação, a assistência educacional à pessoa privada de liberdade limita-se, infelizmente, a pouco mais de $10 \%$ da população prisional, conforme dados do Infopen (DEPEN, 2018). Não diferente do sistema prisional, o socioeducativo, embora previsto no ECA e no Sistema Nacional de Atendimento Socioeducativo - SINASE (Brasil, 2012) como obrigatório o acesso a educação para os adolescentes e 
jovens em cumprimento de medidas socioeducativas, a educação escolar não é garantida a todos. Lamentavelmente, como já evidenciado em publicações anteriores (JULIÃO, 2016; JULIÃO, GODINHO, RODRIGUES, 2018), há diversos avanços legais que não se consolidam efetivamente por meio de políticas públicas que garantam o direito à educação em espaços de privação de liberdade.

Contribuindo para a divulgação e socialização do tema, ainda tão invisibilizado pela sociedade em geral e pelo campo acadêmico, vários artigos do dossiê Educação e Privação de Liberdade ilustram os impasses e desafios que os contextos socioeducativo e prisional representam para a sociedade em geral, educadores de jovens e adultos, gestores e demais operadores do sistema de garantias de direitos e das políticas de restrição e privação de liberdade. Outros apresentam possibilidades de reflexão sobre o trabalho docente, experiências educativas com adolescentes, jovens e adultos privados de liberdade, possibilitando-nos a reflexão sobre as diversas práticas e os diferentes sujeitos da EJA em contextos de privação de liberdade.

Abrindo o dossiê, o artigo "Produção Artesanal com Mulheres em Prisões: Reflexão e criatividade superando a lógica patriarcal" analisa uma experiência de produção artesanal no contexto da extensão universitária. As reflexões desenvolvidas sobre o encarceramento feminino, segundo a autora, oferecem "subsídios para (re)pensar a produção artesanal como prática criativa e reflexiva, questionando a lógica patriarcal que essas atividades tendem a assumir”.

No segundo artigo, "Educación en Cárceles: Práctica alienante o liberadora", analisa uma experiência educativa em contexto prisional, desenvolvida em Cali, Colômbia. Com base na experiência colombiana, tão pertinentes também à realidade do sistema prisional brasileiro e sul americano, o autor provoca-nos a pensar sobre a possibilidade da educação no cárcere inserir-se em um projeto de ressocialização ou ser libertadora à medida que provoque reflexões sobre as condições de vida e, desse modo, possibilitar a transformação dos sujeitos apenados.

No terceiro artigo, através do texto "O Panoptismo e os Discursos das Professoras em uma Instituição Escolar do Cárcere na Fronteira", buscou-se refletir sobre as práticas de professoras que atuam no sistema penitenciário a partir do Panoptismo de Bentham (1793). Segundo os autores, "os resultados evidenciam a discrepância quanto ao ambiente de aprendizagem prisional em um mesmo município, bem como os reflexos da docilização que o panoptismo traz aos sujeitos, alunos(as) e professoras, em suas formas de controle, se distanciando muitas vezes de suas finalidades e propósitos".

Com base nas narrativas de professoras que atuam no sistema prisional no estado de Mato Grosso, no artigo "Docência no Sistema Penitenciário: O que as narrativas de professores revelam sobre a Educação de Adultos Privados de Liberdade" também refletem sobre a docência em contextos de privação de liberdade. Em linhas gerais, os autores partem da realidade deste estado para refletir sobre as especificidades da função docente na EJA em contextos de privação de liberdade.

Já com enfoque na política socioeducativa, o artigo "Portas Fechadas no Meio Aberto: Educação de jovens com restrição de liberdade" analisa a retomada das trajetórias escolares por jovens que cumprem medida socioeducativa de meio aberto. Os autores consideram que a escola não 
recebe ou dificulta o retorno destes adolescentes e jovens aos estudos escolares por conta do preconceito contra quem cometeu ato infracional. Embora reconhecida no ECA como a "rainha das medidas socioeducativas", infelizmente, na prática, as medidas de meio aberto são ainda menos valorizadas pelo poder público e pela sociedade, necessitando de mais estudos que colaborem com a sua implementação na prática.

Em análise da realidade da política de restrição e privação de liberdade do estado do Amazonas, os autores através do artigo "O Direito à Educação para Pessoas em Situação de Restrição e Privação de Liberdade" refletem sobre as políticas públicas de garantia de direito à educação em contextos de restrição e privação de liberdade. Os resultados da análise da política, conforme os autores, evidenciam "a negligência do Estado mínimo no atendimento ao direito à educação de pessoas em situação de restrição e privação de liberdade, uma ação que interfere nos 62 municípios do Amazonas".

No artigo "Educação de Jovens e Adultos em Privação de Liberdade - Escutando vozes silenciadas", os autores, a partir de três diálogos entre apenados em regime semiaberto e docentes, desenvolvem reflexões sobre a experiência de escolarização de jovens e adultos em três instituições prisionais brasileiras. As conclusões do estudo indicam que "persiste uma visão preconceituosa de parte dos professores em relação a esses educandos; essa visão se estende, inclusive, à relevância e necessidade dessa modalidade de educação".

No artigo "A Docência em "Celas de Aula". Desafios dos professores de Educação Física em escolas prisionais", destacam-se as contradições entre os propósitos da educação física nas salas de aula do contexto prisional e as limitações impostas pelas condições de trabalho na prisão. Segundo os autores, "os docentes revelaram vários desafios, destacando-se os limites para o desenvolvimento de suas ações com a Educação Física, em razão das aulas acontecerem somente dentro da sala/cela e com diversas restrições". No cotidiano de trabalho destes docentes, as aulas práticas ficam estritamente limitadas e as suas condições extremamente restritas.

O artigo, "Celas e Salas: A recente produção acadêmica sobre educação escolar na prisão (2003-2017)", apresenta uma pesquisa bibliográfica que buscou analisar a produção acadêmica estrito senso brasileira sobre educação escolar nas prisões. A pesquisa mapeou produções acadêmicas (teses e dissertações) disponíveis nas plataformas da BDTD-IBICT e da CAPES. As autoras ressaltam que "evidencia-se que apesar de garantias legais, a educação escolar no sistema prisional é problemática, ainda que parte dos sujeitos acreditem em seu papel ressocializador. Conclui-se que o tema permanece como objeto a ser pensado e problematizado na atualidade". Embora tenha crescido o número de estudos nas áreas das ciências humanas e sociais sobre o tema, há ainda muito que precisa ser investigado.

O último artigo aborda a educação física em uma unidade da socioeducação de Campinas. As autoras de "Privação de liberdade e educação: desafios de uma professora de educação física na medida socioeducativa de internação" consideram que "diversos são os dispositivos de segurança e de 
controle que regulam o cotidiano institucional e que, diante de uma rígida e cautelosa organização, o(a) próprio(a) docente passa por constantes processos de adaptação".

Além dos artigos, o dossiê apresenta uma entrevista com a professora Analía Umpierrez da Faculdade de Ciências Sociais da Universidade Nacional do Centro da Província de Buenos Aires Argentina: "A experiência Argentina de oferta de Ensino Superior no Sistema Prisional". Na entrevista, a educadora, uma importante interlocutora do tema na América do Sul, traça um panorama histórico da educação em contextos de privação de liberdade em seu país, o que nos permite compreender as condições socio-históricas em que se aprovou a criação de cursos de nível superior nas prisões argentinas, uma extraordinária experiência de educação nas prisões, considerada modelo para vários países no mundo. Além disso, Analía reflete sobre a situação atual do ensino superior no cárcere e os desafios futuros, considerando a conjuntura política do país, que não difere do Brasil e de vários países da América do Sul, enfrentando uma onda de políticas conservadoras que defendem uma redução nos investimentos em políticas sociais em detrimento de políticas meramente preocupadas com as questões econômicas e de segurança pública que visam o controle das massas empobrecidas.

Por fim, a resenha "O fazer literário com a matéria do por vir" discute a obra Vidas Aprisionadas - Relatos de uma prática educativa, de Maria Salete van der Poel, lançada em 2018 pela Editora Oikos.

Através do dossiê Educação e Privação de Liberdade da Revista Reflexão e Ação, esperamos que a leitura propicie a ampliação do debate sobre o direito à educação em espaços de restrição e privação de liberdade nos diferentes regimes de cumprimento de pena e medidas socioeducativas e a visibilização das questões e especificidades vivenciadas nas diferentes experiências implementadas nos estados do Brasil. Entendemos que a reunião de estudos que abordam estas distintas realidades, permite ao leitor ou leitora conhecer a variedade de abordagens teóricas, de perspectivas práticas, assim como de sujeitos e seus olhares sobre os sistemas.

Longe de esgotar o tema, este dossiê possibilita compreender a complexidade do tema e os inúmeros desafios a serem ainda enfrentados à garantia do direito à educação em contextos de restrição e privação de liberdade.

Boa leitura a todos! 